\title{
Food and Diseases in Zanzibar
}

Eating habits and practices in relation to the prevalence of diet-related chronic non-communicable diseases in Zanzibar

\section{Amélie Keller}

\section{Q OpenEdition \\ 1 Journals}

\section{Electronic version}

URL: https://journals.openedition.org/eastafrica/502

DOI: 10.4000/eastafrica.502

ISSN: 2790-1076

\section{Publisher}

IFRA - Institut Français de Recherche en Afrique

\section{Printed version}

Date of publication: 1 July 2012

Number of pages: 87-115

ISSN: 2071-7245

\section{Electronic reference}

Amélie Keller, "Food and Diseases in Zanzibar", Les Cahiers d'Afrique de l'Est / The East African Review [Online], 45 | 2012, Online since 07 May 2019, connection on 09 December 2021. URL: http:// journals.openedition.org/eastafrica/502 ; DOI: https://doi.org/10.4000/eastafrica.502 


\title{
Food and Diseases in Zanzibar
}

\author{
Eating habits and practices in relation to the \\ prevalence of diet-related chronic non-communicable \\ diseases in Zanzibar
}

Amélie Keller

\begin{abstract}
This article explores the association between fruit \& vegetables eating habits and the prevalence of diet related chronic non-communicable diseases in Zanzibar, such as diabetes, hypertension and obesity. It shows that daily intakes of fruit \& vegetables are well below standards recommended by the World Health Organisation. Findings suggest a relationship between rural/urban setting, kitchen facilities, cooking practices, food diversity and diet-related diseases.
\end{abstract}

\section{Introduction}

Obesity, diabetes, some cancers and hypertension are diet-related NonCommunicable Diseases (NCDs). NCDs are the leading cause of deaths in developed countries and account for approximately one-third of deaths in developing ones. The increased of NCDs is due to different socio-economic factors such as industrialisation, urbanisation, economic development and globalisation. Furthermore, the prevalence of NCDs can be linked to a demographic transition that leads to an epidemiological change. In addition, diet-related NCDs are linked to the nutrition transition that involves more energy- dense food and limited physical activity (Kennedy, 2005; Popkin, 2001). Non-communicable diseases increase inequalities because they disproportionately affect poor people. Poverty is also caused by NCDs because of the persisting expenditure related to chronic diseases and loss of productivity (Beaglehole et al., 2011; DeSchutter, 2011).

This article investigate these trends in Zanzibar, an archipelago of the United Republic of Tanzania, a Sub-Saharan African country where, similarly to the other countries of the continent, food habits and cultural behaviours as well as seasonality, post-harvest loss, lack of availability and under-developed food processing constitute impairing factors for fruit \& vegetables consumption. It provides background information about NCDs in Zanzibar before it presents and discusses the research findings. 


\section{Poverty and diseases in Zanzibar, Tanzania}

Zanzibar has a young demographic and high total fertility rate (5.1 children per women) and the annual average population growth rate is 3\% (ZFSNP, 2009). There are large differences and inequalities between rural and urban areas in terms of education, gender roles as well as health outcome and health care facilities (WHO, 2010). As described by Marmot et al. (2008), inequalities in power, income and goods and services distribution are the main causes of health inequities by impairing people's access to health care, education, good housing and working condition as well as socialising and being part of the community.

In Zanzibar, it is estimated that about $49 \%$ of the population lives below the basic needs poverty line (BNPL) (TRGZ, 2007). The poverty incidence is higher in rural areas compared to urban areas with $55 \%$ of people living under the BNPL in the former and $41 \%$ in the latter. However, economic inequality seems to be generally low as the Gini coefficient is estimated to be 0.28 ( $0=$ perfect equality and $1=$ perfect inequality) (TRGZ, 2007).

Education, food production, urbanisation and reduced physical activity account for significant changes related to nutrition. Nowadays, mainly in urban areas, processed and packaged high-fat/high-sugar and low fibre food items are available on the market. Furthermore, people tend to have a lower level of physical activity than they did previously. However, this trend is not confirmed for most Zanzibaris living in rural areas, where food has become scarce and often more expensive and people have physically demanding occupations. Accordingly, Zanzibar is, as other developing countries, undergoing the double burden of underweight and overweight/obesity

As with other developing countries, NCDs such as diabetes mellitus and hypertension are estimated to become the leading cause of morbidity and mortality by 2020 in Zanzibar. Indeed, the incidence of diabetes has increased from 252 new cases in 2006 to 373 in 2008 and more women than men are affected (Jiddawi, 2008; TRGZ, 2010). The rapid rise of diabetes and impaired glucose tolerance amongst the population of Zanzibar (and Tanzania) can be explained by two factors. First, fifty years ago, the use of hospitals was not common, diagnosis was not easy; thus there was minimal data on diabetes prevalence available. Second, nutritional transition due to modernisation and urbanisation has rapidly changed physical activity and diet patterns (Maletnlema, 2006). People moving from a rural area to an urban one experience a shift from high-fibre and low-fat/low-sugar diet and hard work to low-fibre and high-fat/high-sugar with little physical activity which results in weight gain and increased NCDs (Popkin, 2001; Nguma, 2010; Kennedy, 2005).

As diabetes, hypertension is becoming a significant public health problem in Sub-Saharan Africa, especially in urban areas. In Zanzibar, hypertension is the third 
most common cause of hospital admission and second cause of death after pneumonia (Jiddawi, 2008). Cardiovascular diseases and diabetes together with injuries and dental cases account for the highest "number of non-communicable death problems reported at hospitals" TRGZ (2010: 43). As in other developing countries, a steady increase of obesity and hypertension problems was recorded in diabetic clinics (TRGZ, 2010). According to the Zanzibar Food Balance Sheet Report for the year 2007 (2009), 27\% of women of reproductive age in Zanzibar are either overweight or obese due to inadequate food intake and lack of physical activity that predispose to diabetes and hypertension (ZFSNP, 2009).

\section{Food security and diet in Zanzibar}

Poverty and food insecurity are interlinked. Poverty is present in both rural and urban areas. Indeed, 13\% of Zanzibar population lives below the food poverty line (9\% in urban areas and 16\% in rural areas) and 49\% lives below the basic need poverty line (41\% in urban areas and 55\% in rural areas). Hunger as well as malnutrition is caused by poverty, but poverty also results from lack of nutritious food intake (RGZ, 2008). In Zanzibar both rural and urban areas have a high prevalence of food and nutrition insecurity. As well as in other African countries, food insecurity is, amongst others, due to poor land management that results in high dependency on food purchased across and outside the Island (Wise and Murphy, 2012). According to the Zanzibar Food Security and Nutrition Situation Analysis (ZFSNSA) (2006) in peri-urban areas of Unguja, 80\% of the household food requirement is purchased and $60 \%$ in peri-urban areas of Pemba. Whereas, in rural areas between " $35 \%$ and $60 \%$ of household food consumption is satisfied by household's own production” (ZFSNSA, 2006; RGZ, 2008).

Between $60 \%$ and $70 \%$ of the Zanzibar work force is employed in the agriculture sector, which contributes to $27.3 \%$ of the GDP. Thus, Zanzibar's economy strongly relies on agriculture. However, only one third of land is suitable for agricultural production, the rest being of coral soil (ZFSNP 2009, Karume 2010). The agriculture sector is characterised by small-scale producers who mostly cultivate food crops such as cassava, banana, sweet potato, legume, maize, millet, sorghum and rice as well as some tropical fruits and vegetables. The majority of smallholder producers is women who generally do not have the opportunity to acquire adequate capacities and resources to improve productivity (Karume, 2010, RGZ, 2008). According to Karume (2010) and the Zanzibar food balance sheet report for the year 2007 (ZFSNP 2009), smallholder producers are facing many difficulties such as poor access to fertile land, agricultural inputs and credit such as harvest and handling technology as well as seasonality of production, small-scale irrigation, inadequate transportation and poor storage facilities. Furthermore, the land production capacity is largely underexploited.

Post harvest losses are high and contribute to food insecurity and import dependence. Indeed, a large proportion of the vegetables, and to some extent fruits, consumed in Zanzibar is imported from main land Tanzania. According to the ZFSNSA (2006) and Mlingi \& Rajab (2009), 41\% of Zanzibar food annual requirement is 
imported and this trend is exacerbated by the development of the tourism industry. Some estimates show that $80 \%$ of vegetables and $20 \%$ of fruits supplied to tourist hotels and restaurants are imported. As a result, Zanzibar's farmers do not benefit from the tourism industry that could be an important source of income. Another estimate from ZFSNP (2009) reports that the total food products import has increased to reach $50 \%$. Rice, sugar and wheat and maize flours are the main foodstuffs imported. Rice is widely consumed and accounts for the largest proportion of food expenditure (15\%-40\% of annual food needs). This situation makes people vulnerable to any variation arising in the rice market (RGZ 2008, Karume 2010, ZFSNP 2009, ZFSNSA 2006).

In brief, food production in Zanzibar is insufficient to meet the population needs and guarantee food security. The lack of agriculture development and high dependence in food imports has socio-economic and health impacts by contributing to poverty and malnutrition. It is estimated that about $13 \%$ of Zanzibar population has difficulties to reach the minimum 2200 daily calories required per adults and are therefore considered as food poor.

According to the 2004-2005 Demographic and Health survey reported in the Zanzibar Food Balance Sheet Report (2009), the majority of people eats three meals per day (two third) and one third eats two meals per day. Cereals represent the most important food group in Zanzibar and account for about $56 \%$ of all caloric intakes and $54 \%$ of all protein intakes. Pulses, tree nuts and seeds are also an important component of the diet and represent $3.8 \%$ of all calories supply and $8.6 \%$ of protein supply. Vegetal products form the basis of the diet and are more widely consumed than animal products. Vegetal products represent $92 \%$ of all calories and over $72 \%$ of proteins food supply in Zanzibar. Fish is the main source of animal protein and represent $16 \%$ of all protein and contributes to $2.3 \%$ of all caloric intakes. In Zanzibar, meat consumption is really seldom and thus is not an important source of proteins and fats (ZFSNP, 2009). Additionally, low fruit $\&$ vegetables intake as well as the high consumption of rice and wheat (refined carbohydrates) is associated with NCDs (Hu et al., 2012). Mlingi \& Rajab report that many fishers do eat very little if any vegetables as long as they have fish and that fruits are usually consumed as a snack when available and are usually not part of the meal (ZFSNSA, 2006; Mlingi \& Rajab, 2009). On the other hand, the low consumption of meat may be a protective factor, as moderate protein consumption and substitution of red meat with poultry and fish is associated with a reduced risk of hypertension and cancer (Roberts, 2005; Pan et al., 2012).

\section{Research Question}

The primary focus of this study is to assess the fruit \& vegetables consumption situation in Zanzibar in relation to the prevalence of obesity, diabetes and hypertension. What observable social components, behaviour and food habits hinder fruit \& vegetables consumption that is a contributing factor for the development of NCDs? In order to answer this question, four objectives were formulated: 
1. To analyse the association between fruit $\&$ vegetables intake and the prevalence of obesity, diabetes and hypertension in rural and urban areas;

2. To observe fruit \& vegetables eating habits and practices of ten different households;

3. To investigate factors influencing the quantitative assessment of fruit \& vegetables during the NCD survey;

4. To analyse gender differences in fruit \& vegetables intake in relation to obesity, diabetes and hypertension.

\section{Methodology}

A mixed methods research with triangulation of quantitative and qualitative data was adopted. This form of triangulation helps "support a finding by showing that independent measures of it agree with it, or at least, do not contradict it" (Miles, 1994). For the quantitative component of the study, a secondary analysis of data previously collected from the national NCD survey was undertaken. The selected data from the NCD survey were analysed using SPSS 20. In the NCD survey, the following questions were asked to participants in order to measure fruit $\&$ vegetables consumption:

In a typical week, on how many days do you eat fruit?

How many servings of fruit do you eat on one of those days?

In a typical week, on how many days do you eat vegetables?

How many servings of vegetables do you eat on one of those days?

In order to obtain the average number of servings of fruit or vegetable per day $(\mathrm{N}(\mathrm{fv})$ the following calculation was made:

$$
\frac{\mathrm{N}(\mathrm{fv})=\mathrm{Nd} \times \mathrm{Ns}}{7}
$$

Where $\mathrm{Nd}=$ Number of days per week with fruit or vegetables consumption and Ns $=$ Number of servings of fruit or vegetable on one of those days.

Daily consumption of fruits and vegetables was divided into two categories: low consumption; recommended consumption. Frequency, percentage and 95\% Confidence Intervals (CI 95\%) were calculated for each of the following covariates: age, gender, marital status, level of education, income, tobacco use, alcohol use, obesity (BMI), hypertension (SBP\&DBP) and diabetes (Fasting Blood Glucose). Each covariate was divided into two sub-categories to see if there were any statistically significant differences between them.

Two by two tables with odds ratio, P-value and relative risk (RR) were used when $95 \% \mathrm{CI}$ where not overlapping between daily consumption of fruits and vegetables and each covariate. This was done in order to assess whether the results (difference between the two groups) was statistically different or not.

To perform the independent sample t-test, continuous variables were used. A prerequisite of the independent sample t-test is that the variables are normally 
distributed. As the current variables from the NCD survey were not normally distributed, the square root of each variable was used. The independent sample t-test was performed for fruit \& vegetables intake "low and recommended consumption" and gender "men and women" for the following variables: income, waist to hip ratio (WHR), Body Mass Index (BMI), systolic blood pressure (SBP), diastolic blood pressure (DBP), fasting blood glucose (FBG) and age. These variables were the ones for which the P-value was $<0.05$ in the two by two tables. Furthermore, independent sample t-test was performed regarding obesity and BP as well as obesity and fruit \& vegetables consumption in both rural and urban areas. Finally, analysis of variance was used to further assess the association between hypertension and fruit \& vegetables intake as a negative association was found (Pearson correlation).

For the qualitative component of the study, direct observations (household and market observations) were undertaken. The qualitative research describes and explains the downstream relationships between the social and cultural determinants established through the quantitative secondary data analysis. This type of mixed method research is useful to identify people's knowledge, attitudes, practices and beliefs and gives an appraisal of the nature of the areas in which the survey was conducted. Direct observations entitle the researcher to uncover the everyday routine of participants and discover what they "take for granted" and the rationality behind their practices and behaviours. Being on site allows the researcher to familiarise with the environment and the people. It also provides the opportunity to describe situations in details and participate in events, which enable the researcher to see and feel how things are organised, where priorities are put, how much time is spent on an activity and check definition of terms used by the participants (Bryman 2008, Kawulich 2005).

Primary data collection and analysis using formal structured direct observations were conducted between January and March 2012. Questions were asked using an unstructured interviewer's guideline while the observations were conducted to clarify and get an in-depth understanding of people's consumption of fruits and vegetables. The observations took place in participants' households in rural and urban areas on Unguja Island. The observations were done with the help of a Swahili-English interpreter when participants could not speak English. The researcher shared food with ten different households and observed food preparation, food eating, food wasting as well as the family structure such as who is eating with whom and the number of family members. The researcher also conducted market observations regarding fruit \& vegetables purchase. The observations were made at Darajani market, which is the main retail market in Stone Town. As it is a retail market it was more convenient to witness customers who buy food items for their households. In order to do the market observations, several visits at the market at different times of the day were made to observe the buying/selling process such as who buy fruits and vegetables (men or women), what the prices are and how fruits and vegetables are displayed/sold (packaging/refrigerated/quantity/quality). 
- Sample Design: For the quantitative part of the survey, the sample size of the NCD survey was calculated to be 2800 individuals. The sampling technique used in the NCD survey was a multi-stage cluster sampling with stratification. For the qualitative part, the sample population was selected to cover a wide range of variations, contrasts and differences, thereby providing profuse and various qualitative data. By doing so, a variety of nuances could be appraised. The study sites were evaluated and discussed with the Ministry of Health in Zanzibar in order to conduct observations in both rural and urban areas. The findings from the qualitative part of the study were triangulated with the literature and the findings from the quantitative part of the study.

- Study sites: The study sites were on Unguja Island. The market observations took place in Darajani market in Stone Town. Four household observations took place in Bwejuu (rural area), one household observation took place in Kiembe Samaki (suburb of Stone Town), two observations took place in the city centre of Stone Town, one observation took place in Mwarakewereke Meli Nne (west suburb of Stone Town) and the last observation took place in Kizimkazi (rural area).

- Rural areas: Bwejuu is a small village on the southeast cost of Unguja Island. The majority of men are either fisherman, farmer (cassava and lime) while women grow seaweed or work as cleaning lady in hotels. The land is not fertile as it is made of coral. Kizimkazi is a village on the southwest cost of Unguja Island. Inhabitants are usually fisherman and/or farmers and the developing tourism sector provides employment as well. The land is fertile, thus growing crops is less problematic than in Bwejuu.

- Urban areas: Stone town is the old centre of Zanzibar city, that is, the capital of Zanzibar. As it is an urban setting, citizens do not generally cultivate any fruits or vegetables and rely on Darajani market for their fruit \& vegetables provision. Mwarakewereke Meli Nne and Kiembe Samaki are part of Zanzibar city and therefore are urban areas. Being on the outskirt of Stone Town, people rely on either Mwarakewereke or Darajani markets.

- Households' social aspects: The four women in the rural area of Bwejuu were married and had between three and four children. Five to seven people were living together in one household and participants were Muslims. In Kiembe Samaki, suburb area of Stone Town, the woman was married and had four children, six people were living in the household and they were Muslims. In the city centre, one household was composed of two Hindu elderly women. In the other household a divorced man (Hindu) lived with three foreigners to whom he rented rooms. His two children were coming for lunch almost every day at his place. In Mwarakewereke Meli Nne, suburb of Stone town, nine people from an extended family were living in the same house (couple, children and relatives). In Kiembe Samaki, seven people lived together (couple, four children and the wife's sister) and in Kizimkazi, six people were living together (couple and four children). The three households from the suburbs were Muslim. 


\section{Presentation of findings}

Table 1: Mean \pm SD for Age, BMI, SBP, DBP, FBG, WHR, F\&V intake, Education an Income(National NCD survey, Zanzibar 2012)

\begin{tabular}{|l|l|l|l|l|l|l|l|}
\hline Data & $\mathrm{N}$ & Minimum & Maximum & Mean & \pm SD & Mean Men & Mean Women \\
\hline Age (years) & 1362 & 25.0 & 65 & 42 & 11.4 & 43.3 & 41.3 \\
\hline BMI $^{1}$ & 2606 & 12.7 & 64.9 & 24.4 & 5.5 & 23.4 & 25.1 \\
\hline SBP $^{2}$ & 2634 & 40.0 & 246 & 135.4 & 26.7 & 138.9 & 133.3 \\
\hline DPB $^{3}$ & 2634 & 30.0 & 148 & 79.4 & 14 & 79.2 & 79.6 \\
\hline FBG $^{4}$ & 2462 & 1.2 & 31 & 4.4 & 1.6 & 4.4 & 4.3 \\
\hline WHR $^{5}$ & 2389 & 0.4 & 1.9 & 0.9 & 0.1 & 0.9 & 0.9 \\
\hline Vegetable intake $^{6}$ & 2645 & 0.0 & 3.4 & 0.7 & 0.6 & 0.6 & 0.8 \\
\hline Fruit intake & 2466 & 0.0 & 6 & 0.9 & 0.8 & 1 & 0.9 \\
\hline Education (years) & 2657 & 0.0 & 25 & 6.7 & 4.9 & 8.9 & 5.4 \\
\hline Income (TSH) & 1020 & 1.0 & $41,700,000$ & 176,433 & $1,611,478$ & 233,731 & 129,366 \\
\hline
\end{tabular}

1. Body Mass Index

2. Systolic Blood Pressure

3. Diastolic Blood Pressure

4. Fasting Blood Glucose

5. Waist to Hip Ratio

6. $\mathrm{Nb}$ of servings of vegetables per day

7. $\mathrm{Nb}$ of servings of fruits per day

8. Monthly income $(1,000 \mathrm{Tsh}=0.6 \mathrm{USD})$

The total sample size was 2'800 of which 38\% were male and the mean age was 42 years old $( \pm S D 11.4)$. There were more people living in rural areas $(69 \%)$ compared to urban ones $(31 \%)$. The mean years of education was 6.7 ( \pm SD 4.9$)$ and the mean monthly income was 176,433 Tsh. $(=110 \$)( \pm$ SD 1,611,478) (Table 1).

The mean fruit intake was less than one serving per day, 0.9 ( \pm SD 0.8$)$ and mean vegetable intake was less than one serving per day, 0.7 ( \pm SD 0.6). Regarding obesity, blood pressure and diabetes, the mean BMI was 24.4 ( \pm SD 5.5) and the mean waist to hip ratio was 0.9 ( \pm SD 0.1$)$. Interestingly, there was three times more obese women $(19.4 \%)$ than men $(6.4 \%)$ in the sample population (based on BMI $\geq 30$ $\mathrm{Kg} / \mathrm{m} 2$ ) (Table 2). The mean systolic blood pressure was 135.4 ( \pm SD 26.7) and the mean diastolic blood pressure was 79.4 ( \pm SD 14). Furthermore, 38\% of men and 33\% of women were hypertensive, which represents more than one third of the sample population (Table 2). The mean fasting blood glucose level was 4.4 ( \pm SD 1.6) and 2.2\% of men and $2.8 \%$ of women were diabetic (based on FBG test alone) (Table 2). 
Table 2: Number and percentage of obese, hypertensive and diabetic people divided by gender (National NCD survey, Zanzibar 2012)

\begin{tabular}{|l|l|l|l|l|}
\hline \multirow{2}{*}{} & \multicolumn{2}{|c|}{ Men } & \multicolumn{2}{c|}{ Women } \\
\cline { 2 - 5 } & $\mathrm{N}$ & $\%$ & $\mathrm{~N}$ & $\%$ \\
\hline Hypertensive & 383 & 37.6 & 535 & 32.6 \\
\hline Diabetic & 22 & 2.2 & 46 & 2.8 \\
\hline Obese & 65 & 6.4 & 318 & 19.4 \\
\hline
\end{tabular}

\subsection{Fruits and vegetables local definition and meaning}

The market as well as household observations revealed that Zanzibaris categorised vegetables into two groups: leafy-vegetables and fruit-vegetables. In the common understanding of people from Zanzibar the word 'vegetable' relates to leafyvegetables such as cassava leaves or spinach and when people refer to other types of vegetables such as aubergines or cucumber, they use the term fruit-vegetables.

"For us, vegetables are leaves, like cassava or spinach. If you talk about carrots people use the word fruit-vegetable" (woman from household $\mathrm{n}^{\circ} \mathrm{6}$ ).

"Ab! Here in Zanzibar, if you say vegetables, people understand leaves, the others are called fruit-vegetables" (Nutrition Unit staff)

Regarding fruits, no sub-categories were observed. Therefore, it is interesting to note that the meaning regarding the term 'vegetable' is different in Zanzibar compared to most European countries where no such sub-categories exist. As an example in the questionnaire used for the NCD survey, fruits and vegetables were divided into two categories, but no sub-categories were included. Hence, one can stipulate that some difficulties might have arisen during the quantitative data collection.

In the present article, the term vegetable is used to describe both leafy- and fruitvegetables and the term leafy-vegetable vs. fruit-vegetable is used when distinction between the two categories is required.

\subsection{Availability o cost of fruits and vegetables in Zanzibar}

The consumption of less than one serving of fruit $(m=0.9)$ and less than one serving of vegetable $(m=0.7)$ per day can be explained by the availability and cost of fruits and vegetables observed at Darajani market during the market observations as well as at local retailers as part of the household observations. The following chapter starts by describing Darajani market place and the availability and prices of fruits and vegetables in rural and urban areas. An analysis regarding the relationship between fruits and vegetables availability and prices and people's consumption follows.

Darajani market place is a concrete building forming a squared enclosure with stalls inside (Figures 1 and 2). The market is divided into three sectors: fish area, meat area and fruits and vegetables area. Fruits and vegetables are either sold on mats on the 
ground, small tables, baskets, carts or wooden stalls and were displayed by type of fruits or vegetables as illustrated in figures 3 and 4 . Outside the enclosure there are lots of other stalls and people who sell items on mats or directly on the ground. The majority of fruits and vegetables are displayed inside the concrete building; however, fruits and vegetables are also available outside the concrete space (Figures 1 and 2).

Figure 1: Outside view of Darajani Market
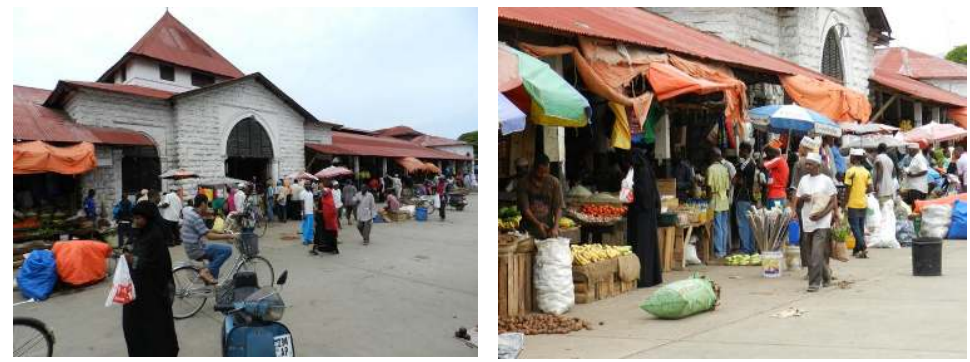

Figure 2: Inside Darajani market
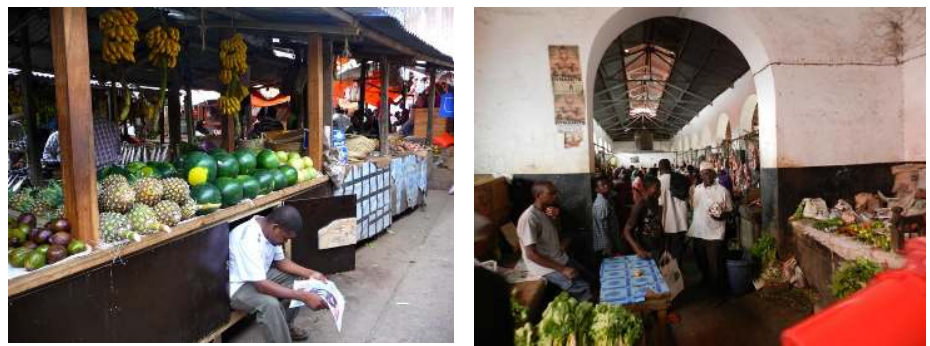

At Darajani market as well as at the local retailers observed, there was not any packaging and items were either put in plastic bags or paper bags when sold. Furthermore, all fruits and vegetables were sold raw. Foodstuffs such as fruits and vegetables, meat and fish were displayed at ambient temperature $\left(+30^{\circ} \mathrm{C}\right)$, either directly exposed to the sun or in the shade. The observations indicate that the lack of cold storage facilities and the tropical climate were two factors impairing fruit and vegetables freshness and quality. Storing fruits and vegetables seemed problematic for retailers as well as customers. To illustrate, three households in rural areas and one in urban area as well as people at Darajani market reported that vegetables tend to be bought for the same day or at most, kept for the following day. The reasons given were related to the heat and lack of cold storage facilities:

"Vegetables don't last long, because it is hot here in Zanzibar [...] not like your country (referring to European countries)" (a man at the market)

"You know, most people they don't have fridge, so you can't keep things very long" (woman household $n^{\circ} 2$ ) 
For the same reasons, household members in rural areas were saying that there was generally no leftover as everything was eaten the same day:

"I cook everyday for the same day, it's hot here and the food becomes not good if I keep it for too long" (woman from household $\mathrm{n}^{\circ} 3$ ).

As the prices of fruits and vegetables varied according to item's freshness and quality, retailers' income was affected. Indeed, when fruits or vegetables are a bit rotten or damaged, the price usually goes down from $20 \%$ to $50 \%$ of the initial price (depending on one's bargaining aptitude). Consequently, due to the potential income losses, retailers are concerned about the lack of cold storage facilities that impair the quality of their products:

"When it's black or not looking nice, I don't make money" (a banana and coconut retailer at Darajani market)

"If it was colder, I'd make more money because now I need to throw away things or sell for almost nothing, so I don't make good money" (a fruit \& vegetables retailer at Darajani market)

\subsection{Fruits and vegetables available at Darajani market and at local retailers}

The market observations revealed a diversity of fruits and vegetables available, which suggests that customers had an array of choices, and thus were not limited by a lack of variety (Figure 3). As opposed to the urban area of Stone town, there was not any market in the rural areas of Bwejuu and Kizimkazi; only small merchants were selling fruits and vegetables. The variety of fruits and vegetables observed at local retailers in both sub-urban and especially rural areas suggest that customers, who depended on local retailers for their fruits and vegetables supply, were more restrained in their choice than people who could purchase items at Darajani market (Figure 4).

The household observations showed that participants living in the rural areas of Bwejuu and Kizimkazi depended almost entirely on local retailers for the purchase of fruits and vegetables. In the areas of Kiembe Samaki and Mwarakewereke Meli Nne (suburb of Stone Town) participants reported to buy most of the fruits and vegetables at the market in Darajani or Mwarakewereke. However as it was necessary to go by vehicle to both markets for all households, the local retailers were frequently used for last minute purchases. In the centre of Stone Town, both households' participants reported to buy their food items, especially fruits and vegetables at Darajani market or in small shops across the centre. As Darajani market was at a walking distance for both households (5-10 minutes on foot), its access was easier in terms of allocated time and money for participants living in the city centre compared to participants living in suburban and rural areas. 
Figure 3: Fruits and Vegetables at Darajani market
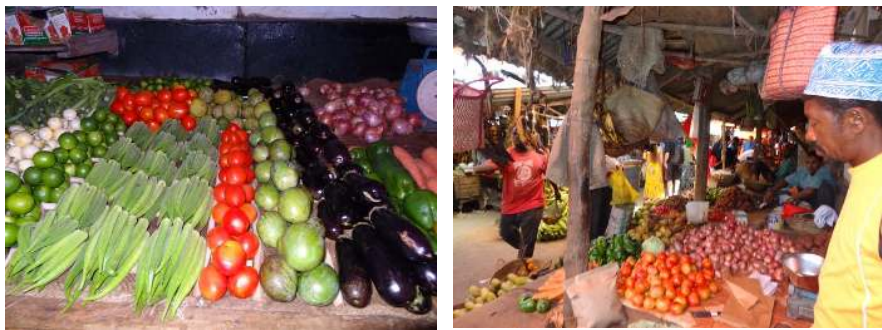

Figure 4: Fruits and vegetables available at local retailers
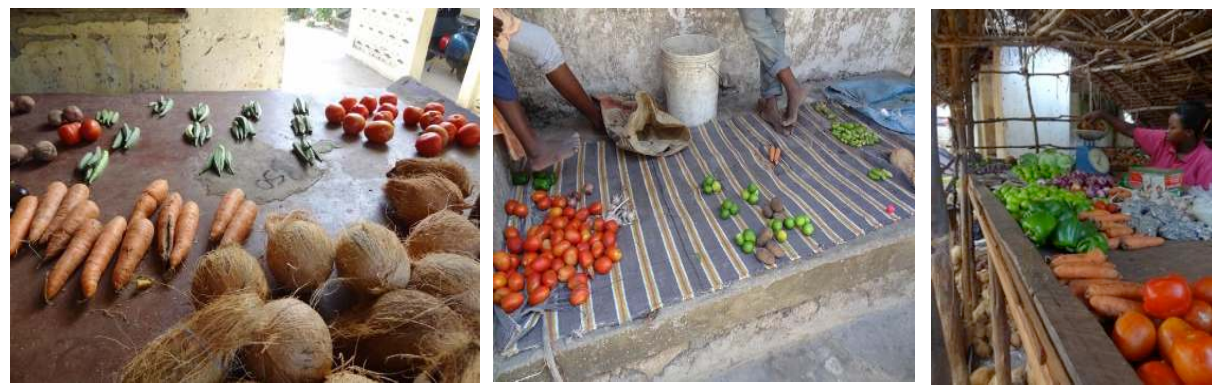

The availability of fruits and vegetables depends on the season. As an example, the tomato season was reported to be between July and September, thus during those three months tomato supply was said to be plentiful. However at the time of the observations, between January and March, tomatoes were imported from the Mainland and the quantity of tomatoes available on the Isles was reported to be smaller and prices higher:

"Now it's not the tomato season, we have to import from Tanzania so prices are very bigh" (a merchant at Darajani).

"February is not a good month, it's the season for nothing and everything [fruits and vegetables] is expensive" (a customer at Darajani market).

Although availability of fruits and vegetables plays a crucial role in their consumption, price is also an important component to consider in relation to consumption. To the participants interviewed, vegetables were very expensive and two women reported that they could not afford to cook vegetables everyday. Considering that the mean monthly income in Zanzibar is 176'433 Tsh. and that people from rural areas earn on average 4.5 times less than in urban ones (Table 3), the cost of fruits and vegetables is high. To illustrate, in household $n^{\circ} 1$ the woman was reporting that more 
than $2 / 3$ of her total expenditure was for food:

Woman from household n¹: "Almost all I earn is to eat"

Researcher: "Do you know what part of your budget it represents?"

Woman from household n¹: "Maybe 60 or $70 \%$ "

Table 3: Income in rural vs. Urban areas

\begin{tabular}{|c|c|c|c|c|}
\hline & & $\mathrm{N}$ & Mean & Std. Deviation \\
\hline \multirow{3}{*}{ Monthly income } & Urban & 317 & $382,064.9$ & $2,875,975.6$ \\
\cline { 2 - 5 } & Rural & 703 & $83,708.1$ & $136,307.9$ \\
\hline
\end{tabular}

Furthermore, according to one informant, the monthly minimum wage in Zanzibar was raised early this year from $70 ’ 000$ Tsh. $(=44 \$)$ to $140 \prime 000(=88 \$)$ in order to adjust to the increasing cost of living. To illustrate, a broad estimate of the cost of fruits and vegetables indicate that in order to reach the minimum recommended amount of $400 \mathrm{~g}$ per day, if all the items were purchased at Darajani market, the cost would be comprised between 600 and 800 Tsh. per person. Reported to one month, these sums (18000 and 24000 Tsh.) account for one third of a minimum monthly salary of 70'000 Tsh. and about one sixth of a minimum monthly salary of 140'000 Tsh.

If people from rural areas involved in the observations wanted to buy vegetables elsewhere, they had to take a local transport (daladala) and go to town at Darajani or Mwarakewereke markets. Mwarakewereke was the market where the village merchants were buying their items; therefore prices at the village were more expensive due to the transportation costs as well as retailers' profit margin. Indeed, prices were generally $20 \%$ to $50 \%$ more expensive than at Darajani market: "I buy the things at the market, so here it's a bit more expensive. I need to live!" (a local retailer).

In other words, the observations demonstrated that the availability of fruits and vegetables was more limited at local retailers and that these retailers were more expensive than other vendors (Darajani market). Additionally, people from rural areas were more dependent on these retailers as a source of fresh produce. Indeed, fruits and vegetables seemed to be generally expensive as a proportion of mean incomes (176'433 Tsh.). The cost was particularly high for people living in rural areas that not only had to pay more for fruits and vegetables and had fewer choices, but also had a much lower income than people from urban areas. 


\subsection{Kitchen facilities and food diversity in rural and urban bousebolds of Zanzibar}

Kitchen facilities also influence fruit \& vegetables consumption and food diversity. The more kitchen utensils available and the better the kitchen facilities (electricity, storage facilities and running water), the easier it is to prepare different dishes concurrently. Participants with multiple kitchen facilities seemed more likely to prepare and eat a more diverse diet with more vegetables than people with poorer facilities.

In Bwejuu, houses were made of bricks and mud with palm leaves on the roof whereas in Kizimkazi they were made of bricks, concrete and aluminium sheets on the roof. In both villages, the households where the observations took place had one or two taps with running water and two out of five households had electricity (Table 4). In the five households the kitchens were open space with a roof, outside in the courtyard (Figure 5, left side). Women cooked using typical Zanzibar metallic saucepans and used firewood. The fire was on the ground and women were alternatively sitting on low wooden stools or squatting on the ground (Figure 7). Knifes, spatulas, spoons, graters, pans, saucepans, sieves and plastic bowls were seen to be used as kitchen tools in the five households (Figure 6). Neither oven nor fridges were seen in Bwejuu whereas the household visited in Kizimkazi had a fridge and freezer. The fridge was half empty and the other half was filled with bottled water and soda. Therefore the fridge was not used to store food items.

Figure 5: Open kitchen in rural area (left side) vs. closed kitchen in urban area (right side)
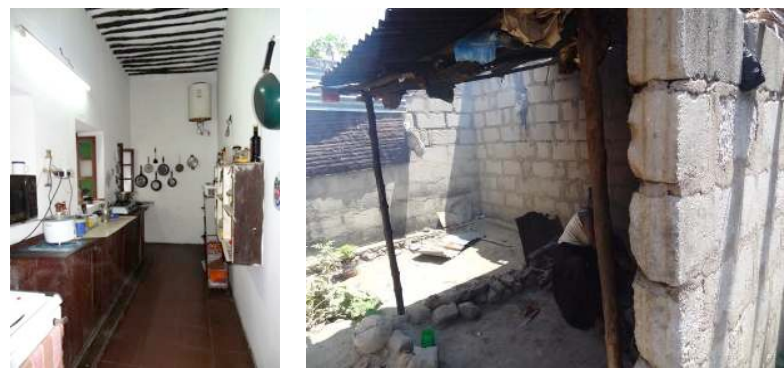

Figure 6: Contrast between kitchen utensils in rural areas (left side) and urban areas (right side)
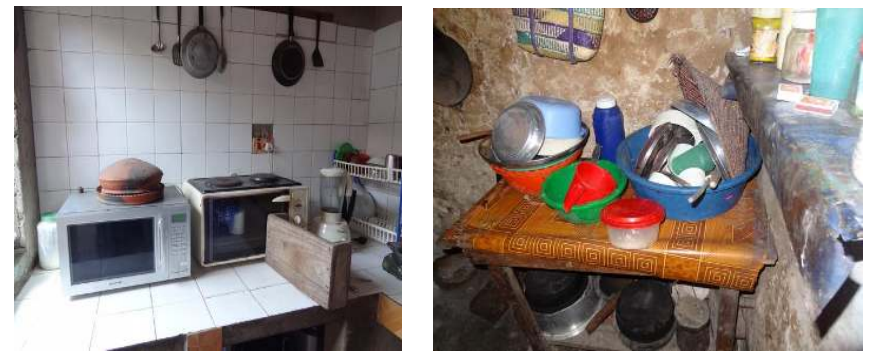
Figure 7: Cooking process in rural (left side), sub-urban (middle) and urban areas (right)
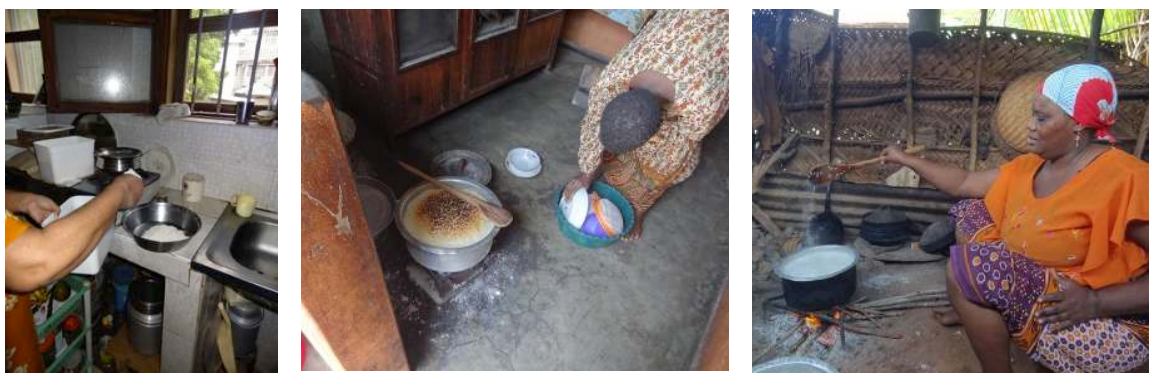

Figure 8: Contrast between rural (left side) and urban kitchens layout (right side)
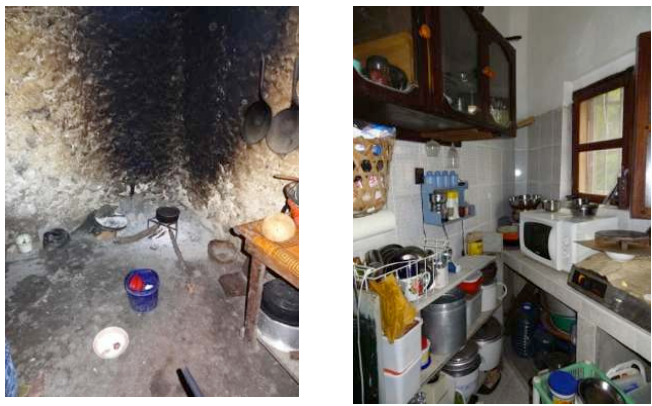

In the suburb and central part of Stone Town visited, the houses were made of bricks and concrete. As opposed to households in rural areas, the houses where the observations took place each had a living room with a TV and stereo and electric facilities that indicate that the urban areas visited were comparatively more affluent. In three of the households the kitchens were in a semi-open space inside the house or in the yard. The other two kitchens were in a closed and separated space with windows (Figure 5 and 8, p.34-35).

Three of the households had an oven and automatic electric cookers, all had stoves (electric and/or gas), a microwave, a blender, frying pans, sauce pans and many kitchen tools (Figure 6 and 8 right sides). All households had at least one fridge (Table 4). Similar to the household from Kizimkazi, the fridge was used to refrigerate water or sodas in three of the households and only in two of the households was the fridge used to store food such as vegetables and dairy products. Those findings suggest that despite having access to cold storage facilities, some participants were not using them to store fruits and vegetables. The reason given by one of the woman was related to the frequent electricity cuts. However, in the two other households it appeared that participants had the habit of purchasing fruits and especially vegetables on a daily basis, thus did not need to store them. 
Three of the households had taps (indoor and outdoor) connected to a well and the others had running water (Table 4). During the observations none of the participants used their oven and one used their microwave to reheat leftovers. In the three households from sub- urban areas, the women (mother and daughter) cooked on charcoal on the ground using Zanzibar saucepan and frying pan; whereas in the two households from the city centre participants used both electric and gas stoves.

Two out of three households in sub-urban areas had electric stoves but did not use them and all three households used charcoal to cook as opposed to firewood in rural areas and electric stoves in the households from the city centre :"T have the electric stoves, but I prefer the fire [charcoal], that's how I learnt to prepare food" (woman from household nº).

Therefore, the observations suggested that cooking practices as well as storing practices not only depended on the facilities available, but were linked to tradition and habits. Nevertheless, cooking facilities, especially in terms of number and diversity of utensils available, seemed related to the variety of dishes prepared. Indeed, the household observations showed that an average of 3.4 different dishes were prepared in participants' households from urban areas compared to an average of 2.8 in rural ones. Similarly, more vegetables were prepared in urban areas compared to rural areas.

Table 4: Cooking facilities in ten households in rural and urban areas of Zanzibar (National NCD survey, Zanzibar 2012)

\begin{tabular}{|c|c|c|c|c|c|c|c|c|}
\hline Household & Electricity & $\begin{array}{l}\text { Running } \\
\text { water }\end{array}$ & $\begin{array}{l}\text { Own } \\
\text { well }\end{array}$ & $\begin{array}{l}\text { Electric } \\
\text { cooker }\end{array}$ & $\begin{array}{l}\text { Gas } \\
\text { cooker }\end{array}$ & Firewood & Charcoal & Fridge \\
\hline 1 & & & & & & & & \\
\hline 2 & & & & & & & & \\
\hline 3 & & & & & & & & \\
\hline 4 & & & & & & & & \\
\hline 5 & & & & & & & & \\
\hline 6 & & & & & & & & \\
\hline 7 & & & & & & & & \\
\hline 8 & & & & & & & & \\
\hline 9 & & & & & & & & \\
\hline 10 & & & & & & & & \\
\hline
\end{tabular}

\subsection{Gender and age differences regarding fruit \& vegetables preparation and consumption}

This paragraph describes and analyses gender and age differences regarding fruit \& vegetables consumption and preparation. The mean number of days with consumption of fruits in a week was 3.9 (3.7 for women and 4.2 for men). The majority of people ate less than one serving of fruits per day (58.9\%) (Figure 9) and more women ate less than one serving of fruits per day (62.3\%) than men $(52.5 \%)$. Furthermore, 
$77.8 \%(75.6 \%$ men and $80.5 \%$ women $)$ of the people had a low intake of serving of fruits. The difference between men and women consumption of servings of fruits was statistically significant when comparing "low intake" vs. "recommendations". However this difference was small as men were only $6 \%$ less likely than women to have a low fruit consumption (P-value 0.003: $\mathrm{RR}=0.94$ ). In brief, more women than men had a low consumption of fruits however, despite being statistically significant, it was not substantially significant.

The mean number of days with consumption of vegetables in a week was 2.8 (2.9 for women and 2.6 for men). The majority of people ate less than one serving of vegetables per day (76.7\%) (Figure 9) and the percentage of women who ate less than one serving of vegetables per day was lower $(74.3 \%)$ than men $(80.5 \%)$. The vast majority of people $(99.2 \%$ men and $98.6 \%$ women) had a low intake of servings of vegetables per day. However, the difference between men and women consumption of servings of vegetables was not statistically significant when comparing "low intake" vs. "recommendations". Men and women were as likely to have a low consumption of vegetables (P-value 0.193; RR 1.006). In brief, more men than women had a low consumption of vegetables but it was not statistically significant.

Figure 9: Men vs. women number of servings of fruits and vegetables per day (National NCD survey, Zanzibar 2012)
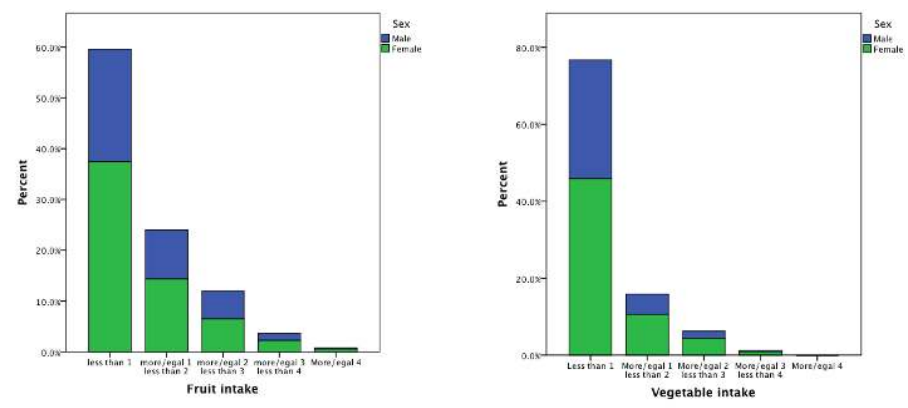

As aforementioned, no differences regarding gender and age in terms of amount of fruits and vegetables consumed were observed during the household observations. However, gender differences were noticed regarding food purchase, food preparation and eating process at lunchtime.

The market and household observations revealed that more men than women purchased food items: "It is usually men who go to the market, because in our culture women are not allowed, but now it is changing so you can see some women at the market" (F. one of the informants). 
However, in nine of the ten households visited, women decided what should be bought: "Women they tell the men what to buy, they usually decide what to cook" (F. one of the informants)

In nine of the ten households visited, only women were seen cooking: "In the Swabili tradition, it is women's duty to cook and take care of the household and men's duty to bring money to the housebold" (F. one of the informants).

Regarding eating, in eight of the households, dishes were placed on a tray and people ate from the different plates and bowls with their right hand (Figure 10 and 11). One plate was shared between two to three people. Women and men, when eating together, were not sharing the same plates. In seven of the households, men were allocated a bigger portion of rice than women; however no differences in terms of quantity of vegetables allocated could be observed.

These findings suggest that even though men go to the market, women decide what should be bought and are also in charge of cooking. The observations suggest as well that vegetables are not considered nutritious and therefore as men need to eat more, only food considered as nutritious should be eaten in greater proportion. As people are sharing plates, assessing the portion eaten by one individual is likely to be more difficult than when people have their own plates.

Figure 10: Main meal food display in urban (left) rural (middle) and sub-urban (right) households
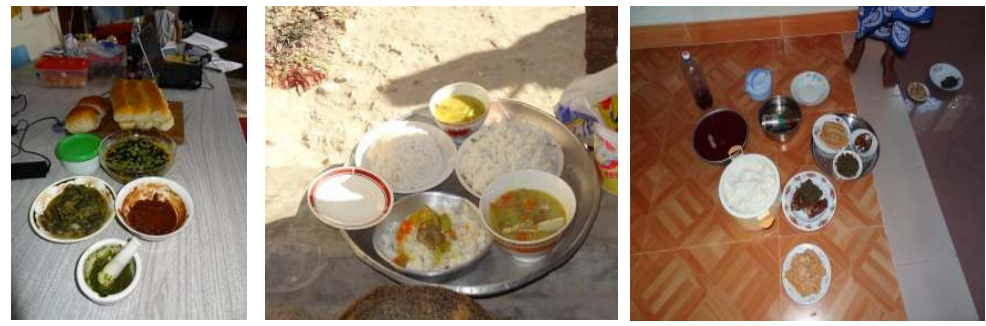

Figure 11: Eating process - people sharing plates in the rural area of Bwejuu

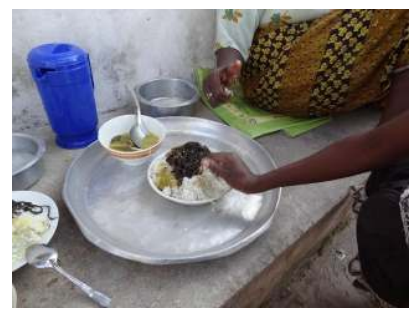


Vegetable intake and age were positively associated for men and women $(\mathrm{r}=0.058, \mathrm{p}=0.034, \mathrm{R} 2=.0033)$. Fruit intake and age were negatively associated for men and women $(\mathrm{r}=-0.058, \mathrm{p}=0.041, \mathrm{R} 2=.0033)$. Thus as age increased, the consumption of vegetables increased and the consumption of fruits decreased. However, due to the small $\mathrm{R}^{2}(0.33 \%)$, the trend is not of a size that matters to individuals' health.

Regarding fruit consumption, $76 \%$ of the $25-44$ years old group and $81 \%$ of the 45-64 years old group had a low consumption of fruits. Accordingly, about $23 \%$ of the 25-44 years old group and 18\% of the 45-64 years old group met the recommendations. The difference between the two age groups was statistically significant, however limited. Indeed, people aged between 25-44 years old were 6\% less likely than people aged 45-64 years old to have a low fruit consumption (P-value $=0.006$; RR 0.94). In brief, younger people (25-44 years old) had a higher consumption of fruits than older ones (45-64 years old). Nevertheless, even if statistically significant, the difference was not substantially significant.

The majority of the 25-44 years old group (99\%) and 45-64 years old group (98\%) had a low consumption of vegetable. However, the difference between the two age groups was not statistically significant (P-value $=0.58 ; \mathrm{RR}=1.003$ ). In brief, the low consumption of vegetables was very common amongst both age groups.

\subsection{Association between NCDs and fruit of vegetables consumption in rural and urban areas}

There are large differences between rural and urban areas in terms of income, housing and cooking facilities as well as fruits and vegetables availability and price. Regarding obesity, hypertension and diabetes, rural/urban differences exist as well (described below). Furthermore, differences in term of type of food prepared and eaten were also observed during the household observations.

\subsubsection{Obesity}

Associations between obesity, hypertension and diabetes regarding fruit \& vegetables consumption were found. Indeed, $83 \%$ of obese people and $77 \%$ of nonobese people had a low fruit intake. Accordingly, only $16 \%$ of obese and $22 \%$ of nonobese met the recommendations. The difference between obese and non-obese consumption of servings of fruits was statistically significant when comparing "low intake" vs. "recommendations". Thus obese people were more likely than non-obese to have a low fruit consumption (P-value $=0.01$; RR 1.075). 98\% of obese and non-obese people had a low consumption of vegetable and 1\% in both group had an adequate intake. The difference between obese and non-obese people was not statistically significant (P-value $=1$; RR 1.002). Therefore, the low consumption of vegetable was very common amongst obese and non-obese people. 
When computing correlations, fruit \& vegetables intake was positively associated with BMI ( $\mathrm{r}=0.057, \mathrm{p}=0.05, \mathrm{R} 2=.0033$; $\mathrm{r}=0.076, \mathrm{p}=0.000, \mathrm{R} 2=.0058$ ). Similarly, the independent t-test showed that people with a higher vegetable consumption had a higher BMI $(\mathrm{MBMI}=24.6, \mathrm{SE}=0.81)$ than participants with lower vegetable consumption $(\mathrm{MBMI}=24.1, \mathrm{SE}=0)$. However, this difference was not statistically significant (P-value 0.58). On the other hand, the independent t-test showed that people with a low fruit consumption had a higher BMI $(\mathrm{MBMI}=24.25, \mathrm{SE}=0)$ than participants with recommended consumption $(\mathrm{MBMI}=23.66, \mathrm{SE}=0)$. This difference was statistically significant, $\mathrm{p}<.05$. In brief, correlation analysis showed that there was a positive association between BMI and fruit \& vegetables intake, suggesting that the higher the fruit \& vegetables consumption, the higher the BMI (or inversely). However, findings from the t-test showed that the higher the BMI, the higher the vegetable consumption and the lower the fruit consumption. These differences might be explained by the generalised low consumption of fruits and especially vegetables and related general weak r-correlations. There was a large difference in the prevalence of obesity between urban and rural areas with three times more obese in urban areas compared to rural ones. Indeed, $26 \%$ of people from urban areas were obese compared to $9 \%$ in rural ones. The mean BMI was also higher in urban areas $(\mathrm{MBMI}=26.4)$ compared to rural ones $(\mathrm{MBMI}=23.4)$. This difference was statistically significant $\mathrm{p}<0.05(\mathrm{P}=0.000)$ (Table 5).

BMI was also positively associated with income for men ( $\mathrm{r}=0.095, \mathrm{p}=0.044$, $\mathrm{R} 2=.0009)$ and women $(\mathrm{r}=0.091, \mathrm{p}=0.034, \mathrm{R} 2=.0083)$. Therefore, people with higher income had an increased BMI. Fruit \& vegetables intake was also positively associated with income for men and women $(\mathrm{r}=0.068, \mathrm{p}=0.038, \mathrm{R} 2=.005)$. Thus, as income increase, consumption of fruits and vegetables increase.

\subsubsection{Hypertension}

Regarding hypertension, $80 \%$ of people with hypertension had a low intake of fruits and $98 \%$ had a low intake of vegetables. In comparison, $76 \%$ of non-hypertensive people had a low fruit intake and $98.5 \%$ a low intake of vegetables. The difference was statistically significant for fruit intake. Indeed, when analysed separately for DPB and SBP, people with elevated SBP (P-value 0.016; RR 1.29) and DBP (P-value 0.007; RR 1.071) were more likely to have low fruit consumption compared to the other group. However, this difference was small (increased risk of $7 \%$ and $5 \%$ respectively). The difference was not statistically significant for vegetable intake (DBP: P-value 0.353; RR 0.995; SBP: P-value 0.447; RR 0.996).

When computing correlations, fruit intake was negatively associated with DBP ( $\mathrm{r}=$ $0.042, \mathrm{p}=0.037, \mathrm{R} 2=.0018)$ and SBP $(\mathrm{r}=-0.072, \mathrm{p}=0.000, \mathrm{R} 2=.0052)$ for men and women. Thus as the consumption of fruit increased, the blood pressure decreased. In figures 12 and 13, box-and-whisker plots, the analysis of variance (ANOVA) showed that people who ate less than one portion of fruit per day had a higher mean SBP $(M=136.87 \mathrm{mmHg})$ and DBP $(M=79.98 \mathrm{mmHg})$ than people who ate more than one portion of fruit per day. This trend was reverse for vegetable intake and people who ate 
less than one portion of vegetables per day had a lower SBP $(M=135.25 \mathrm{mmHg})$ and DBP $(\mathrm{M}=79.13 \mathrm{mmHg})$ than people who ate more than one portion of vegetables per day.

Figure 12: Box-and-whisker plot of blood pressure and fruit intake (National NCD survey, Zanzibar 2012)
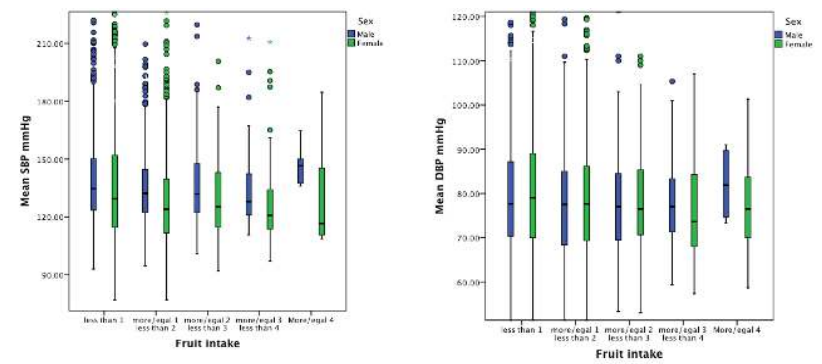

Figure 13: Box-and-whisker plot of blood pressure and vegetables intake (National NCD survey, Zanzibar 2012)
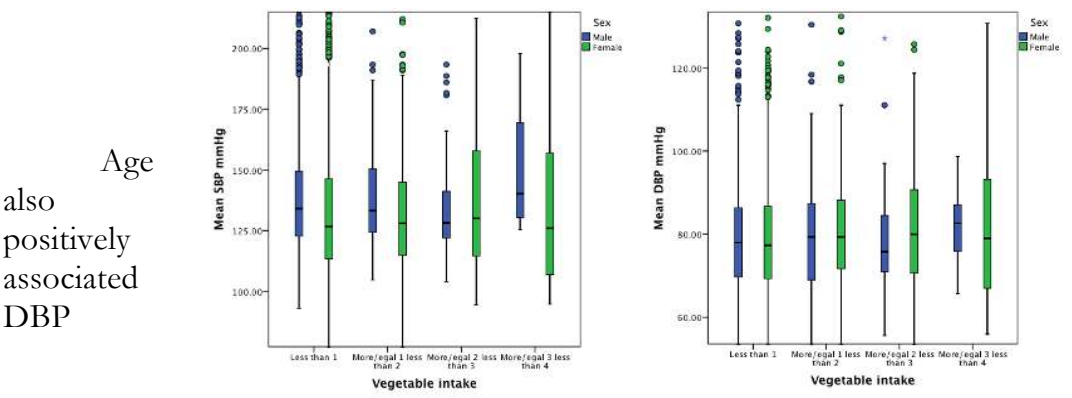

was

$(\mathrm{r}=0.299, \mathrm{p}=0.000)$ and SBP $(\mathrm{r}=0.456, \mathrm{p}=0.000, \mathrm{R} 2=.21)$ for men and women. Thus, as age increased, blood pressure increased. SBP and DBP were positively associated for men and women $(r=0.811, \mathrm{p}=0.000, \mathrm{R} 2=.66)$. Thus, as SBP increased, DBP increased as well or inversely. BMI was positively associated with DBP $(r=0.244, p=0.000, R 2=.06)$ and SBP $(\mathrm{r}=0.136, \mathrm{p}=0.000, \mathrm{R} 2=.01)$ for men and women. The same trend was present for WHR and DBP $(r=0.203, p=0.000, R 2=.04)$ and SBP $(r=0.203, p=0.000, R 2=.04)$ for men and women together. Thus, as age, BMI and WHR increased, blood pressure increased.

Regarding blood pressure differences between rural and urban areas, the mean DBP was higher in urban areas $(M=80.6)$ compared to rural ones $(M=78.9)$ and the difference was statistically significant $\mathrm{p}<0.05(\mathrm{P}=0.003)$. Inversely, the mean SBP was higher in rural areas $(M=136.3)$ compared to urban ones $(M=133.5)$ and the difference was statistically significant $\mathrm{p}<0.05(\mathrm{P}=0.009)$ (Table 5). Furthermore, when assessing the 
association between obesity and BP in urban and rural areas, the mean DBP and SBP was higher amongst obese in both urban and rural areas (DBP urban $\mathrm{M}=86.4$, rural $\mathrm{M}=85$; SBP urban $\mathrm{M}=140.6$, rural $\mathrm{M}=142$ ) than non-obese (DBP urban $\mathrm{M}=78.5$, rural $\mathrm{M}=78.2$; SBP urban $\mathrm{M}=130.7$, rural $\mathrm{M}=135.6$ ) and it was statistically significant $\mathrm{p}<0.05$. Therefore, obese people in both urban and rural areas were more likely to have a higher BP than non-obese people.

\subsubsection{Diabetes}

Regarding fruit and vegetable intakes and diabetes, $78 \%$ of non-diabetic and $93 \%$ of diabetic people had low fruit consumption. The difference between diabetic and nondiabetic patients regarding fruit consumption was statistically significant (P-value 0.002; RR 1.184). Diabetics were $18 \%$ more likely to have low fruit consumption than nondiabetics.

$98 \%$ of non-diabetic and $99 \%$ of diabetic people had a low vegetable consumption.

The difference between diabetic and non-diabetic patients regarding vegetables consumption was not statistically significant (P-value 0.313; RR 0.988). Therefore, diabetics were as likely to have low vegetables intake as non-diabetics.

FBG and fruit and vegetable intakes were positively associated for men and women $(r=0.023, p=0.273, R 2=.0005)$. Thus as the consumption of fruits and vegetables increased, FBG increased. Regarding diabetes prevalence in rural and urban areas (Table $6)$, there was twice as many diabetics in urban areas (4\%) compared to rural ones $(2 \%)$ however, the mean FBG in both rural and urban areas were the same $(\mathrm{M}=4.3$ and 4.3).

Table 5: BMI, DBP, SBP and FBG in rural vs. urban areas (National NCD survey, Zanzibar 2012)

\begin{tabular}{|l|r|r|r|r|r|r|}
\hline \multirow{2}{*}{ Data } & \multicolumn{3}{|c|}{ Urban } & \multicolumn{3}{c|}{ Rural } \\
\cline { 2 - 8 } & $\mathrm{N}$ & Mean & \multicolumn{1}{|c|}{ SD } & N & Mean & \multicolumn{1}{c|}{ SD } \\
\hline BMI** & 847 & 26.4 & 6.3 & 1759 & 23.4 & 4.8 \\
\hline DBP* & 855 & 80.6 & 14.2 & 1779 & 78.9 & 13.9 \\
\hline SBP* & 855 & 133.5 & 26.2 & 1779 & 136.3 & 26.9 \\
\hline FBG & 796 & 4.3 & .1 & 1666 & 4.3 & .1 \\
\hline
\end{tabular}

$*$ Difference between urban and rural area statistically significant, $\mathrm{p}$-value $<0.05$

**Difference between urban and rural area statistically significant, $\mathrm{p}$-value $<0.001$

The prevalence of diabetes and obesity was higher in urban areas compared to rural ones and the mean diastolic blood pressure was also higher in urban areas but this trend was reversed for systolic blood pressure. The higher urban prevalence of diabetes, obesity and DBP could be related to the differences in terms of variety of food and number of meals per day revealed during the household observations between rural and urban areas. Indeed, participants from the households visited in urban areas reported having between two and three meals per day and the ones from the households visited 
in rural areas reported having between one and three meals per day. The members of one household were saying that when they could afford three meals per day, the first meal of the day (breakfast) was composed of bread or cassava sometimes with small fried fish. Women from three of the urban households explained that the morning and evening meals are called teatime and is made of starch (cassava, rice, bread, buns, etc) with fried fish (Figure 14). In the two households from the city centre, teatime was reported to be consumed in the morning and lunch leftovers where kept in the fridge and reheated for dinner.

Figure 14: One example of teatime: boiled cassava (the two white pieces) and fried fish.

Participants of the household observations in Bwejuu reported that when fish is available, they do not eat vegetables. When there is not any fish they usually eat beans instead. They were also saying that the period when they eat fish everyday is in March and April, when there are plenty of fish, fishing conditions are good and it is the low tourists' season. During the high tourists' season, they sell their catches to hotels:

"When they eat fish [with starch], people are too full to eat vegetables" (F., one informant).

Such variations regarding vegetable consumption due to the "fishing season" was not seen elsewhere. It is therefore interesting to see that vegetables consumption might also be linked to the availability of other non-vegetable and non-fruit foodstuffs. In the ten households, the main meal of the day was composed of one main course and no fruits were eaten as part of the meal. Indeed, fruits are eaten as a snack and are not part of the meal:

"It is not the habit and tradition to eat a dessert here or something sweet. This is why when people eat it [fruits] it is as a snack" (Nutrition office staff).

Indeed, outside of the observation time, people were seen eating jackfruit and Zanzibar apples during the afternoon in the streets.

"People here when they eat fruits, it's during the afternoon and sometimes as a snack other time of the day" (Nutrition office staff).

Furthermore, in all households visited, fruit intake was reported to largely depend on the season. In Bwejuu, one of the women taking part in the observations explained that people eat a lot of mangoes when it is the season because they can have them for free or really cheap. Rice was the most consumed food item, both in terms of quantity and frequency. The vegetables used to make the sauce in five of the households visited were carrots, aubergines, tomatoes, onions and okras. The vegetables were pealed, soak in water for 30 minutes to one hour, chopped and then boiled for at least 30 minutes to make the sauce. Other vegetables observed were aubergine (other 
vegetables in table 6) and leafy vegetables such as spinach (mtorero or mchicha) or cassava leaves that were blended, and then cooked with water or coconut milk and water (Table 6).

Table 6: Food ingredients* used in 10 households at the time of the observations, Unguja

\begin{tabular}{|c|c|c|c|c|c|c|c|c|c|c|c|}
\hline 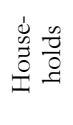 & $\stackrel{\ddot{n}}{\approx}$ & $\begin{array}{l}: 7 \\
5 \\
5\end{array}$ & 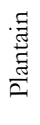 & 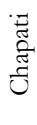 & \begin{tabular}{l}
0 \\
0 \\
0 \\
\multirow{J}{*}{} \\
0 \\
0
\end{tabular} & 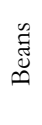 & 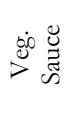 & 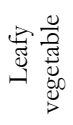 & 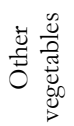 & 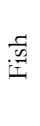 & $\stackrel{\vec{J}}{\vec{J}}$ \\
\hline 1 & & & & & & & & & & & \\
\hline 2 & & & & & & & & & & & \\
\hline 3 & & & & & & & & & & & \\
\hline 4 & & & & & & & & & & & \\
\hline 5 & & & & & & & & & & & \\
\hline 6 & & & & & & & & & & & \\
\hline 7 & & & & & & & & & & & \\
\hline 8 & & & & & & & & & & & \\
\hline 9 & & & & & & & & & & & \\
\hline 10 & & & & & & & & & & & \\
\hline
\end{tabular}

To sum up, the observations and the quantitative data analysis showed that season, availability and price of fruits and vegetables as well as kitchen facilities, cooking practices, income and urban vs. rural settings influence fruit \& vegetables consumption as well as obesity, hypertension and diabetes prevalence. Furthermore, a generalised low consumption of fruits and especially vegetables was present in the NCD survey's sample population and only weak correlations between fruit \& vegetables intake and obesity, diabetes and hypertension were found.

\section{Discussion}

The objectives of this thesis were to analyse the association between fruit \& vegetables intake in relation to the prevalence of obesity, diabetes and hypertension in rural and urban areas as well as to investigate gender differences in fruit \& vegetables intake, obesity, diabetes and hypertension for the quantitative part. The qualitative objectives were to investigate fruit \& vegetables eating habits and practices of ten different households as well as factors that may have influenced the quantitative assessment of fruits and vegetables during the NCD survey.

In order to assess the strengths and limitations of the study, notions of reliability and validity are discussed in relation to the quantitative findings of this thesis. Notions of trustworthiness are discussed for the qualitative findings. To ensure trustworthiness, criteria such as credibility, transferability and dependability are used (Shenton, 2004; Bryman, 2008). Reliability refers to the consistency or repeatability of a measurement whereas validity refers to whether the measurement is accurate or not. Due to the crosssectional design of the NCD survey, causal relationships could not be measured; therefore notion of external, rather than internal validity (generalised to the population) 
will be discussed. Credibility can be used in qualitative research instead of internal validity and refers to how believable the findings are. Transferability is the extent to which the findings of one study can be applied to other settings or groups and corresponds to the external validity in quantitative research. Dependability is similar to the concept of reliability and is the extent to which measures are replicable (Bryman, 2008).

\section{Triangulation of quantitative and qualitative findings}

The results show that one third of the sampled population had blood pressure levels consistent with hypertension $(37.6 \%$ men; $32.6 \%$ women) and three times more women than men were obese (6.4\% men; 19.4\% women). These findings are in concordance with worldwide trends reported in the literature (Kearney et al., 2005, Mponda \& Nyoni, 2012, ZFSNP, 2009). Regarding diabetes, the prevalence (based on fasting blood glucose level only) was $2.5 \%$ and was higher amongst women than men (2.2\% men; $2.8 \%$ women). On the contrary, a study from Wild et al. (2004) showed that the worldwide prevalence of diabetes for all age-groups was $2.8 \%$ with a higher prevalence amongst men and a higher total number of women living with diabetes (Wild et al., 2004). Therefore, both total percentages of diabetics are similar; however there is a difference regarding gender distribution. This difference might be explained by the different measures used to define people as diabetic or not.

The current nutritional trend in developing countries is toward a diet higher in energy with increased consumption of fat, sugar, refined carbohydrate and meat that contributes to an increased risk of diet-related NCDs such as hypertension and diabetes. Urban populations in developing countries are more affected by the nutritional transition and thus have a higher prevalence of diet-related NCDs than rural ones where poverty is higher and people are currently still more affected by under-nutrition (Njelekela, 2003, Schmidhuber \& Shetty, 2005, DeSchutter, 2011). Similarly, the household and market observations as well as the quantitative analysis revealed discrepancies between rural and urban areas in terms of availability and price of fruits and vegetables as well as differences in terms of income, kitchen facilities and prevalence of obesity, hypertension and diabetes. Indeed, access to fruits and vegetables was scarcer in rural areas whereas the prevalence of obesity, hypertension and diabetes was higher in urban ones.

The household observations, quantitative analysis as well as the literature showed that the main staple food in Zanzibar was white rice and that the consumption of fruits and vegetables was low. Low fruit \& vegetables consumption combined with high consumption of refined carbohydrate leads to poor dietary fibre, vitamins, minerals and phytochemicals intake that are chronic NCDs risk factors. As vegetables in Zanzibar are usually pealed, soaked and cooked (boiled) for an extensive period of time, the vitamins and minerals loss is high. Indeed, cooking methods can greatly influence vitamins and minerals food content (FAO/WHO 2004). Inversely, several studies document that a high-fibre diet with consumption of fruits, vegetables, whole grains and low in 
(trans/saturated) fat combined with daily physical activity can prevent (primary prevention) and/or regulate (secondary prevention) hypertension and type 2 diabetes as well as obesity (Roberts, 2005).

Correlation analyses show a positive association between fruit $\&$ vegetables intake, BMI and FBG. These findings are in contradiction with the literature and might be explained by two main different factors. First, as aforementioned, the NCD survey design regarding fruit \& vegetables data collection comprises some limitations. Second, as households become wealthier their diets become more diverse (Weinberger, 2004). Hence it is likely that the higher the income, the more food and food diversity which results in an increased amount of fruits and vegetables as well as an increased amount of high fat/high sugar and low fibre diet with low physical activity which impact on obesity and diabetes as well as hypertension. However, results from the t-test did not support these findings, as obese and diabetics were more likely to have a low fruit consumption than non-obese and non-diabetics. Increased BMI and FBG cannot be explained by an increased intake of fruits and vegetables (weak r-value).

\section{Conclusion}

This study gives an understanding of the relationship between fruit \& vegetables eating habits and practices and their related low consumption. It shows that the consumption of fruits and vegetables in Zanzibar is low and, due to unfavourable cooking habits, the vitamin and mineral intake from fruits and vegetables is impaired. This low consumption can be explained by the restricted availability and high price (compared to people's average income) of fruits and vegetables observed in urban and especially rural areas. Regarding vegetables consumption, the household observations suggest a relationship between kitchen facilities, cooking practices and food diversity as well as consumption of vegetables. Income and kitchen facilities seemed to be associated, hence the consumption of vegetables is likely to be influenced by households' income. As for fruit consumption, it is surprising to note that on a tropical island like Zanzibar where, according to the season, fruits are grown in plenty, people do not have the habit of considering fruits as food but only potential snacks and that fruits are not used in food preparation or preserved. Considering that only weak correlations could be found between fruit \& vegetables consumption and the prevalence of NCDs, further studies are required. Following the National Nutrition Strategy report of the Ministry of Health and Social Welfare of Tanzania, one can nevertheless recommend that nutrition policies and strategies be integrated into various sectors such as health, education, agriculture, community development and industry at national and regional levels. Health promotion programmes should specifically target fruits and vegetables in order to improve their consumption by, for example, teaching cooking methods that preserve vitamins and minerals content, teaching preservation methods (pickles/ chutney) and promote the consumption of fruits not only as a snack, but as part of the meal. 


\section{REFERENCES}

Beaglehole R. et al., 2011. 'Priority actions for the non-communicable disease crisis.' The Lancet 377: 1438-47.

Borchgrevink A., 2003. 'Silencing Language: Of Anthropologists and Interpreters.' Ethnography 4: 95-121.

Bryman A., 2008, Social research Method, Oxford, Oxford University Press.

Campbell M.K., Polhamus B., McClelland J.W., et al., 1996. 'Assessing Fruit and Vegetable Consumption in a 5 A Day Study Targeting Rural Blacks.' I Am Diet Assoc, 96: 1040-1042.

Darnton-Hill I., Nishida C. \& James W.P.T., 2007. 'A life course approach to diet, nutrition and the prevention of chronic diseases.' Public Health Nutrition 7.

De Schutter O., 2011. 'Report Submitted by the Special Rapporteur on the right to food, Olivier De Schutter.' In: UN (ed.) General Assembly-Promotion and protection of all human rights, civil, political, economic, social and cultural rights, including the right to development. UN.

FAO, 1998. Fermented fruits and vegetables. A Global Perspective. In FAO/WHO 2004. Fruit and vegetables for health: Report of a Joint FAO/WHO Workshop. In: DATA, W. L. C.-I.P. (ed.). Kobe, Japan: FAO/WHO.

Granehei U.H. \& Lundman B., 2004. 'Qualitative content analysis in nursing research: concepts, procedures and measures to achieve trustworthiness.' Nurse Education Today 24: 105-112.

Granry, 2009. 'Current Status of Fruits and Vegetables Production and Consumption in Francophone African Countries-Potential Impact on Health.' In: B. Patil (ed.) Promotion of fruits and vegetable for health in francophone African countries. Yaoudé, Cameroon.

Hall J.N., Moore S., Harper S.B. \& Lynch J.W., 2009. 'Global variability in fruit and vegetable consumption.’ Am J Prev Med 36: 402-409 e5.

Hassan A.E., 2011. Zanzibar NCD Survey Data Collection Report. Survey Report for the First National NCD survey in Zanqibar. Zanzibar: Ministry of Health Zanzibar.

Hines A.M., 1993. 'Linking Qualitative and Quantitative Methods in Cross-Cultural Survey-Research-Techniques from Cognitive Science.' American Journal of Community Psychology 21: 729-746.

Hossain P., Kawar B. \& El Nahas M., 2007. 'Obesity and diabetes in the developing world--a growing challenge.’ $N$ Engl J Med 356: 213-5.

Hu E.A., Malik V. \& Sun Q., 2012. 'White rice consumption and risk of type-2 diabetes: meta-analysis and systematic review.' British Medical Journal 344: 1-9.

Huizinga M.M., Carlisle A.J., Cavanaugh K.L., Davis D.L.et al., 2009. 'Literacy, numeracy, and portion-size estimation skills.' Am J Prev Med 36: 324-8.

IDF, 2012. Diabetes [Online]. Brussels. http://www.idf.org/diabetesatlas/5e/diabetes [23.04.2012 2012]. 
Jiddawi M., 2008. Health Management Information System Unit. Health Information Bulletin. Zanzibar: Ministry of Health and Social Welfare, Zanzibar.

Karume A., 2010. Zanzibar Agricultural Transformation for Sustainable Development, 20102020.

Kawulich B., 2005. 'Participant observation as a Data Collection Method.' Forum: Qualitative Social Research (FQS ), 6.

Kearney P.M., Whelton M., Reynolds K., Muntner P., Whelton P.K. \& He J., 2005. 'Global burden of hypertension: analysis of worldwide data.' The Lancet 365: 217 223.

Kelly T., Yang W., Chen C.S., Reynolds K. \& He J., 2008. 'Global burden of obesity in 2005 and projections to 2030.' International Journal of Obesity 32: 1431- 1437.

Kennedy E., 2005. 'The Global face of nutrition: what can governments and Industry do?' Journal of Nutrition 135: 913-915.

Makame M.T., 1993. 'Diabetes in newly diagnosed Zanzibari patients: 1986-1989.' Journal of the national medical association 85: 163-168.

Maletnlema T.N. 2006. 'A Tanzanian perspective on the nutrition transition and its implications for health.' Public Health Nutrition 5.

Miles M.B. \& Huberman, A.M., 1994. Qualitative data analysis. An Expanded Sourcebook. Thousand Oaks, California: SAGE Publications.

Mlingi \& Rajab, 2009. Assessment of Post Harvest Food Losses of Major Food Crops and Fish in Zanzibar: MALE \& FAO.

Mponda \& Nyoni, 2012. 'National Nutrition Strategy July 2011/12 - June 2015/16.' In: Welfare, M.O.H.A.S. (ed.). Tanzania, Ministry of Health and Social Welfare.

Neumark-Sztainer D.E.A., 1996. 'Correlates of Inadequate Fruit and Vegetable Consumption among Adolescents.' Preventive Medicine 25: 497-505.

Nguma, L.K., 2010. Health seeking and bealth related behaviour for type 2 diabetes among adults in an urban community in Tanzania, PhD Thesis, University of Otago.

NHS \& Dietetics, 2012. Diabetes - Dietary Advice for Impaired Glucose Tolerance and Impaired Fasting Glucose. Available: www.nnuh.nhs.uk/viewdoc.asp?ID=760\&t=Leaflet.

NIH, 2003. 'Seventh Report of the Joint National Committee on Prevention, Detection, Evaluation, and Treatment of High Blood Pressure, JNC VII.' In: Services, U.D.O.H.A. H. (ed.) Report of the Joint National Committee on Prevention, Detection, Evaluation, and Treatment of High Blood Pressure.

Njelekela M.E.A., 2003. 'Nutritional variation and cardiovascular risk factors in Tanzania . Rural-urban difference.' South African Medical Journal 93.

Pan A. et al., 2012. 'Red Meat Consumption and Mortality.' Archives of Internal Medicine, 172.

Pomerleau J., Lock K., McKee M \& Altmann D.R., 2004. 'The Challenge of Measuring Global Fruit and Vegetable Intake.' Journal of Nutrition 134: 1175-1180.

Popkin B., 2001. 'The Nutrition Transition and Obesity in the Developing World.' 
Journal of Nutrition.

RGZ, 2008. Zanzibar food security and nutrition policy.

Roberts C.B.R., 2005. 'Effects of exercise and diet on chronic disease.' Journal of Applied Physiology 98: 3-30.

Schmidhuber J. \& Shetty P., 2005. 'The nutrition transition to 2030: Why developing countries are likely to bear the major burden.' In: FAO (ed.) 97th Seminar of the European Association of Agricultural Economists. University of Reading, England.

Shenton A., 2004. 'Strategies for ensuring trustworthiness in qualitative research projects.' Education for Information 22: 63-75.

Souverein O.W., De Boer W.J., Geelen A., Van Der Voet H., De Vries J.H., Feinberg M. \& Vant Veer P., 2011. 'Uncertainty in intake due to portion size estimation in 24-hour recalls varies between food groups.' J. Nutr 141: 1396-401.

TRGZ, 2007. Zanzibar Strategy for Growth and Reduction of Poverty.

http://www.unpei.org/PDF/TZ-zanzibar-strategy-growth-poverty-reduction.pdf [Accessed 23.08.2011].

-2010. Zanzibar Strategy for Growth and Reduction of Poverty 2010-2015. A successor to the Zanzibar Strategy for Growth and Reduction of Poverty 2007-2010 http://www.tzdpg.or.tz/uploads/media/MKUZA_II_FINAL_November_02.pdf [Accessed 25.10.2011].

USCB, 2012. Urban and Rural Classification [Online]. Available: http://www.census.gov/geo/www/ua/urbanruralclass.html.

Weinberger K. \& Msuya J., 2004. Indigenous Vegetables in Tanzania. Significance and Prospects, Shanuan,Taiwan: AVRD.

WHO, 2003. Diet, Nutrition and the Prevention of Chronic Diseases. Technical report series 916. Report of a joint WHO/FAO Expert Consultation. Geneva.

-2010. United Republic of Tanzania: Health Profile.

—2011a. Obesity and Overweight, http://www.who.int/mediacentre/factsheets/fs311/en/

-2011b. STEPwise approach to surveillance (STEPS).

Wild, S. et al., 2004. 'Global prevalence of diabetes. Estimates for the year 2000 and projection for 2030.' Diabetes Care 27: 1047-1053.

Wise T. \& Murphy S., 2012. 'Resolving the Food Crisis. Assessing Global Policy Reforms since 2007.' In: Policy, G.D.A.E.I.A.I.F.A.A.T. (ed.).

ZFSNP, 2009. Zanzibar Food Balance Sheet Report for the year 2007.

ZFSNSA, 2006. 'Zanzibar Food Security \& Nutrition Situation Analysis.' In: Ministry Of Agriculture, L.A.E. \& Welfare, M.O.H.A.S. (eds.). Zanzibar: Revolutionary Government of Zanzibar.

Zimmet P., 2000. 'Globalization, coca-colonization and the chronic disease epidemic: can the Doomsday scenario be averted?' Journal of Internal Medicine 247: 301-310.

Zimmet P., Alberti K.G., Shaw J., 2001. 'Global and societal implications of the diabetes epidemic.' Nature 414: 782-787. 